\title{
On mm'den küçük Proksimal Üreter Taşlarının Tedavisinde Fleksibl ve Semirijid Üreteroskopi Kullanımının Karşılaştırması
}

\section{Comparison of Flexible and Semirigid Ureteroscopy Usage for Treatment of Smaller Than Ten Millimeter Proximal Ureteral Stones}

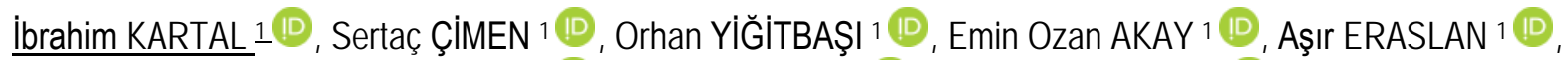 \\ Görkem ÖZZENÇ ${ }^{1}$, Burhan BAYLAN ${ }^{1}{ }^{1}$, Fatih YALÇINKAYA ${ }^{1}$
}

1Sağlık Bilimleri Üniversitesi, Dışkapı Yııdııı Beyazıt Eğitim ve Araştırma Hastanesi, Üroloji Kliniği, Ankara, Türkiye

Öz.

Amaç: On mm ve altındaki proksimal üreter taşlarında cerrahi gerektiren durumlarda fleksibl üreteroskopi ve semirijid üreteroskopi kullanımı sonuçlarının ve güvenilirliğinin değerlendirilmesi amaçlanmıştır.

Materyal ve Metod: Kliniğimizde 2013-2019 arasında 10 mm' den küçük proksimal üreter taşı nedeniyle opere edilen hastaların verileri retrospektif olarak değerlendirildi. Hastalar cerrahide kullanılan üreteroskopi tipine göre fleksibl ve semirijid üreteroskopi grubu olarak ikiye ayrıldı. Her iki grup demografik özellikler, operatif ve postoperatif sonuçlar ve başarı oranları açısından karşılaştırıldı.

Bulgular: On mm'den küçük proksimal üreter taşlarının cerrahisinde kullanılan üretroskopi tipine göre, toplam 382 hastada fleksibl (266) ve semirijid (116) üreteroskopi grupları arasında demografik özellikler ve taş boyutu arasında fark bulunmamaktaydı. Ortalama operasyon süresi fleksibl üreteroskopi grubunda $45 \pm 10,9$ dakika iken semirijid üreteroskopi grubunda $37.2 \pm 10.2$ dakikaydı $(p=0.001$ ). Fleksibl üretroskopi grubunda \%91,4 (266/243) ve semirijid üreteroskopi grubunda \%79,3 (116/92) başarı oranına ulaşıldı $(\mathrm{p}=$ 0.001). Komplikasyon oranları açısından fleksibl $(\% 10,5)$ ve semirijid $(\% 16,4)$ üreteroskopi grupları arasında fark yoktu.

Sonuç: Küçük proksimal üreter taşlarında cerrahi gerektiren durumlarda fleksibl üreteroskopi kullanımı yüksek başarı oranları ile semirijid üreteroskopi kullanımına göre daha avantajıl gözükmektedir.

Anahtar Kelimeler: Fleksibl, Semirijid, Taş, Üreteroskop

\section{Abstract}

Background: In this study, we aimed to investigate the treatment outcomes and safety profile of flexible and semi-rigid ureteroscopy performed for the treatment of proximal ureteral calculi smaller than $10 \mathrm{~mm}$.

Materials and Methods: Patients who underwent ureteroscopy in our clinic between 2013 and 2019 for proximal ureteral stones smaller than $10 \mathrm{~mm}$ were assessed retrospectively. Patients were divided into two groups with regard to ureteroscopy type. Each group were compared in terms of demographic, operative and postoperative parameters and success rates.

Results: No differences were found between flexible (266) and semirigid ureteroscopy (116) groups in terms of demographic features and stone sizes. Mean operative times were $45 \pm 10.9$ minutes and $37.2 \pm 10.2$ minutes for flexible and semi-rigid ureteroscopy groups, respectively. Success rates were \%91,4 (266/243) in flexible ureteroscopy group and \%79.3 (116/92) in semi-rigid ureteroscopy group. No differences were detected in terms of complication rates $(10.5 \%$ in flexible, $16.4 \%$ in semi-rigid group).

Conclusion: Given its high success rate, flexible ureteroscopy appears to be more advantageous than semirigid ureteroscopy for treatment of proximal ureteral stone smaller than $10 \mathrm{~mm}$.
Sorumlu Yazar I

Corresponding Author

\section{Dr. İbrahim Kartal}

Ziraat Mah. Şehit Ömer Halisdemir Cad. No: 20,

Dışkapı Yıldırım Beyazıt Eğitim ve Araştırma Hastanesi, Üroloji Kliniği, Altındağ/ANKARA

Tel: 05556298424

Faks: 03123186690

E-mail: igk84@hotmail.com

Geliş tarihi / Received:

08.08.2019

Kabul tarihi / Accepted: 25.10.2019

DOI: $10.35440 /$ hutfd.602199 


\section{Giriş}

Üreter taşlarında, mevcut kanıtların analizine dayanarak spontan pasaj için boyut açısından kesin bir kestirim değeri olmasa da, $10 \mathrm{~mm}$ en iyi kestirim değeri olarak kabul edilebilir (1). Küçük boyutlu proksimal üreter taşlarında; persistan obstrüksiyonun olması, uygun analjezik tedavisine rağmen ağrı kontrolünün sağlanamaması ve renal yetmezlik gelişmesi gibi durumlarda taşın aktif olarak alınması önerilmektedir (2).

Avrupa kılavuzunda $10 \mathrm{~mm}$ ve altındaki semptomatik proksimal üreter taşlarında aktif taş tedavisi gerektiği durumlarda şok dalga lithotripsi (SWL) veya üreteroskopi (URS) önerilmektedir. Şok dalga lithotripsinin invaziv olmaması, anestezi gerektirmemesi ve ayaktan uygulanabilmesi gibi avantajları mevcut olmakla birlikte, proksimal üreter taşlarında tedavideki yeri hala tartışılmaktadır. Güncel endoürolojik gelişmelerle URS' nin morbiditesinin giderek azaldığı bildirilmektedir ve URS' de tedavi ve iyileşme süresinin daha kısa olduğu bilinmektedir (3). Ayrıca URS tercihi; SWL' nin kontrendike olduğu durumlar yanında, taşın görüntülenmesindeki zorluklar, impakte taş, kalsiyum oksalat monohidrat ve sistin taşı varlığı gibi bazı durumlarda öne çıkmaktadır (4).

Literatürde yapılan çalışmalarda üreter üst kesim taşlarında fleksibl URS (F-URS) kullanımının semirijid URS' ye (S-URS) göre kısa ve uzun dönemde daha yüksek başarı, daha düşük komplikasyon oranları ile daha etkin olduğu bildirilmektedir (5-7). Genelde bu çalışmalarda $2 \mathrm{~cm}$ altı taşlar değerlendirilmiş, $10 \mathrm{~mm}$ ve altındaki taşlar ayrı olarak değerlendirilmemiştir. Biz F-URS' nin proksimal üretrerdeki 10 mm' den küçük taşlarda da S-URS' ye göre avantajının olup olmadığını değerlendirmek için bu çalışmayı hazırladık.

\section{Materyal ve Metod}

On mm ve bu boyuttan küçük tek proksimal üreter taşlarında semirijid ve fleksibl URS kullanımının sonuçlarının ve komplikasyon oranlarıın karşılaştırıması amaçlandı. 2013-2019 arasında kliniğimizde 10 mm' den küçük proksimal üreter taşı olup üreteroskopi yapılan hastaların verileri retrospektif olarak değerlendirildi. Proksimal üreter; sakroiliak eklemin üst sınırı ile üreteropelvik bileşke arası olarak kabul edildi (8).

Gebelik, yaşın 18' den küçük olması, multipl taş varlığı, ipsilateral fonksiyone olmayan böbrek varlığı, üreteral anomalinin bulunması, kanama bozukluğunun varlığı ve teknikleri zorlaştıran vücut şekil bozuklukları çalışmadaki dışlanma kriterleri olarak kabul edildi. Preoperatif internal üreteral stenti bulunan hastalar da çalışmaya dahil edilmedi.

Medikal ekspulsif tedaviden yanıtın alınmadığı, persistan obstrüksiyon varlığının olduğu, renal yetmezliğin geliştiği durumlar ile SWL' nin kontrendike ve başarısız olduğu; impakte taş, kalsiyum oksalat monohidrat ve sistin gibi sert taş hikayesinin varlığı gibi durumlarda hastaların tercihi de göz önüne alınarak URS kararı verildi. Preoperatif olarak tüm hastalara kontrastsız abdomen bilgisayarlı tomografi (BT) çekildi. Taş boyutu aksiyel, koronal veya sagital aksların ölçümündeki en uzun değer olarak kabul edildi. Tüm hastalara preoperatif olarak idrar tahlili ve kültürü testleri yapıldı. Gerektiğinde tüm hastalara uygun antibiyotik tedavisi verilerek işleme alındı.

Hastalar F-URS ve S-URS yapılanlar olarak iki gruba ayrıldı. Üreteroskopi seçiminde standart olmamakla birlikte üreteropelvik bileşkeye yakın ve hidronefrozun eşlik ettiği taşlarda daha çok F-URS tercih edilirken, BT' de üreteropelvik bileşkeden $5 \mathrm{~cm}$ ' den daha uzak görülen taşlarda genelde S-URS tercih edildi. Üretroskopi işlemleri genel anestezi altında gerçekleştirildi. Semirijid URS olarak; 6/7.5 F (Richard Wolf, Knittlingen, Almanya veya Karl Storz, Tuttlingen, Almanya) boyutundaki cihazlar ve lithotripsi için de Medilas H2O holmium laser (Dornier Med-Tech GmbH, Wessling, Almanya) kullanıldı. Fleksibl URS olarak da 7.5-F boyutundaki (Flex X2; Karl Storz $\mathrm{GmbH}$, Tuttlingen, Almanya) cihaz kullanılırken, 20 watt Dornier Medilas H-20 veya 30 watt Medilas H Solvo (Dornier Med-Tech, Wessling, Almanya) holmium laser ile lithotripsi yapıldı. Fleksibl URS grubunda bazı hastalarda 9.5-11 F üreteral akses kllfi (Elit Flex, Ankara, Turkey) kullanıldı. Her iki grupta da double j stent (DJS) cerrahın tercihine göre takıldı.

Her iki grup yaş, cinsiyet, vücut kitle indeksi (VKi), taraf, taş boyutu, operasyon süresi, taşsızlık oranları, hastanede kalış süreleri ve gelişen komplikasyonlar açısından karşıllaştırıldı. Hastalar, postoperatif 1. gün direkt üriner sistem grafisi ve postoperatif 3. ayda BT ile değerlendirildi. Tedavi başarısI; postoperatif 3. aydaki değerlendirmede rezidü fragman olmadan tam taşsızlık veya klinik olarak önemsiz fragman varlığı $(<4 \mathrm{~mm})$ olarak kabul edildi. Tüm işlemler benzer deneyime sahip cerrahlar tarafından gerçekleştirildi. Semirijid URS grubunda; taşın geri kaçmış olması ve prosedürün F-URS ile sonlandırılması başarısızlık olarak kabul edildi, bu hastalar F-URS grubuna alınmadı. Her iki grupta da taşa ulaşılamayarak üretral stent takıııp işlemin ertelenmesi de başarısızlık olarak kabul edildi. Postoperatif komplikasyonlar Modifiye Clavien klasifikasyonuna göre sınıflandırıldı.

İstatiksel analizler SPSS versiyon 20 (SPSS Inc., Chicago, IL) programı kullanılarak yapıldı. Ölçüm verileri ortalama \pm standart sapma olarak verildi. İstatistiksel analizler olarak sürekli değişkenler için Student's t test ve kategorik değişkenler için chi-square testi kullanıldı. $P<0.05$ değeri istatistiksel olarak anlamlı kabul edildi.

\section{Bulgular}

Çalışma kriterlerine uyan, S-URS uygulanan 116, F-URS uygulanan 266 hastanın verileri retrospektif olarak değerlendirildi. Her iki grup arasında cinsiyet, yaş, VKI, cerrahi 
uygulanan taraf ve taş boyutu açısından istatistiksel anlamlı farklılık saptanmadı (sırasıyla $p=0.269, p=0.895$, $p=0.108, p=0.953, p=0.274$ ) (Tablo 1 ).

Tablo 1. Çalışma gruplarının demografik ve klinik özellikleri

\begin{tabular}{llll}
\hline & S-URS (n=116) & F-URS (n=266) & p değeri \\
\hline Cinsiyet (E/K) (n) & $90 / 26$ & $192 / 74$ & 0.269 \\
Yaş (yıl) & $42.1 \pm 14.3$ & $41.9 \pm 13.2$ & 0.895 \\
VKi (kg/m²) & $24.6 \pm 2.5$ & $25.1 \pm 3.2$ & 0.108 \\
Taraf (Sağ/Sol) (n) & $55 / 61$ & $127 / 139$ & 0.953 \\
Taş Boyutu (mm) & $8.3 \pm 1.5$ & $8.5 \pm 1.3$ & 0.274 \\
\hline
\end{tabular}

$\mathrm{E}=$ Erkek, F-URS= Fleksibl üreteroskopi, $\mathrm{K}=\mathrm{Kad}$,

S-URS= Semirijid üreteroskopi, VKi= Vücut kitle indeksi

Operasyon süresi sistoskopun başlangıcından DJS' in takımasının sonuna kadarki süre olarak hesaplandı. Semirijid URS grubunda F-URS grubuna göre operasyon süresi istatiksel anlamlı olarak daha kısaydı $(p=0.001)$. Ortalama hastanede kalış süresi $(p=0.114)$ ve üreteral stent kullanımı ( $p=0.597)$ açısından iki grup açısından istatistiksel anlamlı farklılık tespit edilmedi. Postoperatif 3. ayda yapılan değerlendirmede S-URS grubunda 92 (\%79.3), F-URS grubunda $243(\% 91.4)$ hastada başarı sağlandı ve başarı açısından istatistiksel anlamlı farklılık tespit edildi ( $p=0.001$ ) (Tablo 2).

Tablo 2. Çalışma gruplarının başarı oranları ile operatif ve postoperatif özellikleri

\begin{tabular}{|c|c|c|c|}
\hline & $\begin{array}{l}\text { S-URS } \\
(n=116)\end{array}$ & $\begin{array}{l}\text { F-URS } \\
(n=266)\end{array}$ & $\begin{array}{l}\mathbf{p} \\
\text { değeri }\end{array}$ \\
\hline Operasyon Süresi (dakika) & $37.2 \pm 10.2$ & $45 \pm 10.9$ & 0.001 \\
\hline Hastanede Kalış Süresi (gün) & $1.3 \pm 0.9$ & $1.2 \pm 0.6$ & 0.114 \\
\hline Üreteral Stent Kullanımı (n) (\%) & $\begin{array}{l}97 / 19 \\
(\% 83.6)\end{array}$ & $228 / 38(\% 85.7)$ & 0.597 \\
\hline Başarı (n) (\%) & $\begin{array}{l}92 / 24 \\
(\% 79.3)\end{array}$ & $243 / 23(\% 91.4)$ & 0.001 \\
\hline İntraoperatif komplikasyon (n) (\%) & $14(\% 12.1)$ & $19(\% 7.1)$ & 0.115 \\
\hline Üreteral avülziyon & - & - & \\
\hline Üreteral perforasyon & 2 & 2 & \\
\hline Minör üreteral yaralanma & 12 & 17 & \\
\hline Postoperatif Komplikasyon (n) (\%) & $19(\% 16.4)$ & $28(\% 10.5)$ & 0.109 \\
\hline Ateş & 9 & 13 & \\
\hline Kanama & 6 & 7 & \\
\hline Renal Kolik & 4 & 8 & \\
\hline
\end{tabular}

F-URS= Fleksibl üreteroskopi, S-URS= Semirijid üreteroskopi

Semirijid URS grubunda başarısız olan 26 hastanın 8' inde taş migrasyonu nedeniyle üreteroskopla taşa ulaşılamadı. 11 hastada taşın böbreğe geri kaçması nedeniyle S-URS başarısız sayıldı ve bu hastaların 7'sinde işlem FURS ile tamamlandı. Iki hastada üreteral perforasyon nedeniyle işlem tamamlanmadan, DJS takılıp prosedür sonlandırıldı. Altı hastada da postoperatif değerlendirmede büyük rezidü tespit edildiğinden, bu hastaların 2' sinde F-URS ve 4' ünde SWL işlemi uygulandı.

Fleksibl URS grubunda başarısız olan 23 hastanın 21 'inde dar üreteral segment geçilemediği için taşa ulaşılamadı. Bu hastalara DJS takılıp 15' ine SWL uygulandı. Geri kalan 6 hastaya 2. seans F-URS işlemi yapıldı. Iki hastada taş kırılırken üreteral perforasyon tespit edilmesi nedeniyle üreteral stent yerleştirilip işleme son verildi. Fleksibl URS grubunda 240 (\%90.2) hastada üreteral akses kılıfı kullanıldı.

Her iki grupta da ölüm, avülsiyon, sepsis gibi intraoperatif majör komplikasyonla karşılaşılmadı. Üreteral perforasyon her iki grupta da ikişer hastada izlendi. Bu hastalara DJS takıldı. Sonrasında konservatif tedavi uygulandı ve ek sorunla karşılaşılmadı. Minör üreteral yaralanması olan hastalarda taş kırma işlemi sonlandırımadı. İşlem sonunda bu komplikasyonun geliştiği tüm hastalara DJS takıldı. Postoperatif komplikasyonlar açısından her iki grup arasında istatistiksel anlamlı farklılık tespit edilmedi. Her iki grupta da grade IV ve V komplikasyon gözlenmedi. Postoperatif ateş (grade I) en sık görülen komplikasyon olurken, bu komplikasyon S-URS grubunda 9 hastada, FURS grubunda 13 hastada meydana geldi. Hematüri (grade I) S-URS grubunda 6 hastada görülürken, F-URS grubunda 7 hastada izlendi. Taburculuk sonrası renal kolik gelişen 8 hasta; S-URS grubunda 3 ve F-URS grubunda 5 hasta (grade II) olmak üzere parenteral medikasyon ile tedavi edildi. Parenteral medikasyonla ağrısı kontrol edilemeyen hastalardan, S-URS grubunda 1 ve FURS grubunda 5 hastaya (grade IIIb) DJS takıldı.

\section{Tartışma}

Şok dalga tedavisinin minimal invaziv bir yöntem olmasına rağmen vücut kitle indeksinden olumsuz etkilenmesi, gebelerde ve kanama diyatezi olan hastalarda kullanılamaması gibi dezavantajları vardır (9). Ayrıca $2 \mathrm{~cm}$ altındaki proksimal üreter taşlarının tedavisinde SWL' nin başarı oranının URS' ye göre daha düşük olduğu bir çok çalışmada gösterilmiştir. (10-13). Lopes Neto ve ark. 1 cm' den büyük proksimal üreter taşlarında SWL, URS ve laparoskopik üreterolitotomi modalitelerini karşılaştırdıkları çalışmalarında \%35.7 ile en düşük başarı oranına SWL ile ulaştıklarını bildirmiştir (14). Şok dalga tedavisi; 10 $\mathrm{mm}$ altında da, taş boyutunun küçülmesine ve başarı oranlarının artmasına rağmen URS' nin başarı oranlarını yakalayamamaktadır (15). Salem prospektif çalışmasında $1 \mathrm{~cm}$ ' den küçük proskimal üreter taşlarında SWL' de $\% 80$ başarı oranı bildirmesine rağmen URS 'nin yüksek başarISI ile istatistiksel olarak yine de SWL' nin önünde olduğu göstermiştir (4). Literatüre bakıldığında sadece birkaç çalışmada SWL' de proksimal üreter taşlarının tedavisinde 3. ay sonunda URS ile karşılaştırılabilir başarı oranlarına ulaşıImıştır $(16,17)$. Bu çalışmalarda URS ile erken başarının sağlanıldığı da ayrıca bildirilmiştir. Anlaşılacağı üzere SWL' de taşsızlık oranları zamanla artar. Ancak bu durum geliştirebileceği komplikasyonlarla beraber düşünüldüğünde hastaların iyileşme ve rutin hayata dönme süresini artırmaktadır. Ayrıca yeni yayınlanan bir metaanalizde taş hastalığının tedavisinde URS' nin SWL' ye göre daha uygun maliyetli olduğu bildirilmiştir.

Teknolojinin biyomedikal alana katkısıyla birlikte küçük 
kalibreli ve esnek cihazlar geliştirilmişsir. Ayrıca holmium: YAG laser gibi enerji kaynakları kullanıma sunulmuştur. $\mathrm{Bu}$ gelişmeler ile üreteroskopi ile üreter taşı tedavisinin etkinliği artmış, komplikasyon oranları da azalmışıı (18). $\mathrm{Bu}$ verilere paralel olarak da günlük klinik uygulamalarda küçük proksimal üreter taşlarının tedavisinde URS tercihi gün geçtikçe artmaktadır.

Güncel Avrupa kılavuzunda URS; $10-20 \mathrm{~mm}$ arasındaki taşlarda ilk tercih olarak önerilmektedir (19). Muhtemelen bundan dolayıdır ki, proksimal üreter taşlarının tedavisinde üreteroskopi tipinin etkinliğini karşılaştıran çalışmalar genellikle ortalama 1- $2 \mathrm{~cm}$ boyutundaki taşlar için yapılmış, ayrıca, $10 \mathrm{~mm}$ ve altı taşlar için etkinlik karşılaştıııması yapılmamıştır. Karadağ ve ark. tek proksimal üreter taşlarında S-URS' de \%76, F-URS' de ise \%93 başarı oranı bildirmişlerdir (5). Galal ve ark. tek proksimal üreter taşlarında S-URS' de \%68, F-URS' de ise \%91 taşsızlık oranına ulaşmışlardır (6). Ayrıca Liu ve arkadaşları da FURS ile yüksek başarı oranları bildirmelerinin yanısıra, 4 . lumbar vertebranın üzerindeki seviyelere çıkıldıkça $F$ URS' de S-URS' ye göre daha yüksek başarı oranı yakaladıklarını bildirmişlerdir (20). Bizim çalışmamızda $10 \mathrm{~mm}$ altındaki taşlar değerlendirilmesine rağmen, başarı oranlarımız biraz daha büyük taşları içeren çalışmalarla benzerlik göstermektedir.

Çalışmamızda; prosedürlerin operasyon sürelerini, benzer çalışmalardaki süreler ile karşılaştırdığımızda, operasyon süresinin benzerlik gösterdiğini tespit ettik. Alkan ve ark. çalışmalarında rijid URS yapılan ortalama $9 \mathrm{~mm}$ boyutundaki taşlarda 34 dakika, F-URS yapılan ortalama $8.9 \mathrm{~mm}$ boyutundaki taşlarda ise 49 dakika operasyon süresi bildirmişlerdir (7). Galal ver ark. da rijid URS uyguladıkları ortalama boyutu $13.5 \mathrm{~mm}$ olan taşlarda 41 dakika, FURS uyguladıkları ortalama $12.9 \mathrm{~mm}$ boyutundaki taşlarda ise ortalama 48 dakika operasyon süresi bildirmişlerdir (6). Çalışmamızda F-URS grubunda operasyon süresinin anlamlı olarak uzun bulunması da yine diğer çalışmalarla benzerlik göstermektedir. Bunun nedeni F-URS' den önce bazen dilatasyon amacıyla S-URS kullanılması, üreteral akses kılıfının yerleştirimesi ve ekipman düzeneğinin hazırlanması gibi işlemlerin operasyon süresini uzatması olabilir.

Fleksibl URS grubunda operasyon süresi uzun olsa da, SURS ile kıyaslandığında intraoperatif ve postoperatif komplikasyonlarda artış izlenmemiştir. Aksine istatistiksel olarak anlamlı olmasa da komplikasyon oranı F-URS yapılan hastalarda S-URS grubuna göre daha düşük saptanmıştır. Çalışmamızda her iki grupta 2' şer hastada üreteral perforasyon tespit edilmiş, bunun üzerine kırma işlemleri sonlandırııp DJS takılarak hastalar konservatif izleme alınmışlardır. Bu hastalarda ek sorunla karşılaşılmamıştır. Ek olarak yaşlılarda ve komorbidetisi fazla olan hastalarda F-URS' nin güvenle kullanılabilmesi önemli bir avantajdır (21).
Semirijid URS' nin önemli dezavantajlarından biri de taşın veya fragmanlarının böbrek toplayıcı sistemine geri kaçmasıdır. "Stone cone" kullanımı ve geri kaçışı önleyici bazı manevralar tanımlanmış olsa da, geri kaçış nadir karşılaşılan bir durum değildir. Çalışmamızda S-URS grubunda 11 (\%9.4) hastada taşın geri kaçması gerçekleşmiştir. Literatürde bu durumda izlenecek yol konusunda tartışmalar vardır. Bazı yazarlar URS' nin üreter üzerindeki potansiyel travmatik etkisi ve buna bağlı kanama gibi durumlar nedeniyle F-URS ile bile devam edilmemesi gerektiğini bildirmişlerdir $(20,22)$. Biz hastalarımızın 7' sinde F-URS işlemini devam ettirebildik. Bizim deneyimimiz S-URS ile taş kırmaya başlanan hastalarda taşın geri kaçması durumunda F-URS ile devam etmenin operasyon başarısına katkısı olabileceği yönündedir. Ancak bazı olgularda S-URS ile taş kırma başlandıktan sonra taşın geri kaçması durumunda F-URS ile devam edilmesi net görüş sağlanamaması nedeniyle zor olabilmektedir. Bundan dolayı geri kaçış riski yüksek hastalarda direkt F-URS ile işleme başlamak avantajlı olacaktır.

Çalışmamızın; retrospektif karekteri ve tek merkez deneyimi içeriyor olması başlıca limitasyonlarıdır. Prospektif kontrollü çalışmalar; 10 mm'den küçük proksimal üreter taşlarında F-URS'nin başlıca tedavi yöntemi olarak önerilebilmesi için daha yüksek kanıt düzeyleri sağlayacaktır. Üreteroskopi tercihinde karar verilmesi için önemli bir etken olan maliyet analizinin yapılmaması da çalışmamızın önemli limitasyonlarından bir tanesidir. Bundan sonraki çalışmalarda maliyet analizinin yapılması da özellikle gelişmekte olan ülkelerdeki cerrahlar için yol gösterici olacaktır.

\section{Sonuç}

On mm'den küçük taşlarda S-URS ve F-URS kullanımı oldukça başarılı ve güvenlidir. Küçük taşlarda cerrahi gerektiren durumlarda F-URS kullanımı yüksek başarı oranları ve düşük komplikasyon oranları ile S-URS kullanımına göre avantajlı gözükmektedir. Ayrıca S-URS' nin tercih edildiği olgularda taşın geri kaçtığı durumlarda işleme F-URS ile devam edilebilir.

\section{Finansal Destek:}

Bu çalışmada herhangi bir fon veya destekten yararlanılmamıştır.

\section{Çıkar Çatışması:}

Yok.

\section{Etik Standart:}

Bu çalışmanın katıımcılarına uygulanan tüm prosedürler, kurumsal araştırma komitenin ve 1964 Helsinki beyanına ve daha sonraki değişikliklere uygun etik standartlara göre yapılmıştır. Her hastadan aydınlatılmıs onam formu imzalı olarak alınmıştır. 


\section{Kaynaklar}

1. Preminger GM, Tiselius HG, Assimos DG, Alken P, Buck AC, Gallucci $M$, et al. 2007 Guideline for the management of ureteral calculi. Eur Urol. 2007;52(6):1610-31.

2. Skolarikos A, Laguna MP, Alivizatos G, Kural AR, de la Rosette JJ. The role for active monitoring in urinary stones: a systematic review. J Endourol. 2010;24(6):923-30.

3. Cui $X$, Ji F, Yan H, Ou TW, Jia CS, He XZ, et al. Comparison between extracorporeal shock wave lithotripsy and ureteroscopic lithotripsy for treating large proximal ureteral stones: a meta-analysis. Urology. 2015;85(4):748-56.

4. Salem HK. A prospective randomized study comparing shock wave lithotripsy and semirigid ureteroscopy for the management of proximal ureteral calculi. Urology. 2009;74(6):1216-21.

5. Karadag MA, Demir A, Cecen K, Bagcioglu M, Kocaaslan R, Altunrende $\mathrm{F}$. Flexible ureterorenoscopy versus semirigid ureteroscopy for the treatment of proximal ureteral stones: a retrospective comparative analysis of 124 patients. Urol J. 2014;11(5):1867-72.

6. Galal EM, Anwar AZ, El-Bab TK, Abdelhamid AM. Retrospective comparative study of rigid and flexible ureteroscopy for treatment of proximal ureteral stones. Int Braz J Urol. 2016;42(5):967-72.

7. Alkan E, Saribacak A, Ozkanli AO, Basar MM, Acar O, Balbay MD. Flexible Ureteroscopy Can Be More Efficacious in the Treatment of Proximal Ureteral Stones in Select Patients. Adv Urol. 2015;2015:416031.

8. Frober R. Surgical anatomy of the ureter. BJU Int. 2007;100(4):94965.

9. Desai M, Sun Y, Buchholz N, Fuller A, Matsuda T, Matlaga B, et al. Treatment selection for urolithiasis: percutaneous nephrolithomy, ureteroscopy, shock wave lithotripsy, and active monitoring. World J Urol. 2017;35(9):1395-9.

10. Cui $Y$, Cao W, Shen H, Xie J, Adams TS, Zhang Y, et al. Comparison of ESWL and ureteroscopic holmium laser lithotripsy in management of ureteral stones. PLoS One. 2014;9(2):e87634.

11. Cone EB, Pareek G, Ursiny M, Eisner B. Cost-effectiveness comparison of ureteral calculi treated with ureteroscopic laser lithotripsy versus shockwave lithotripsy. World J Urol. 2017;35(1):161-6.

12. Wu CF, Shee JJ, Lin WY, Lin CL, Chen CS. Comparison between extracorporeal shock wave lithotripsy and semirigid ureterorenoscope with holmium:YAG laser lithotripsy for treating large proximal ureteral stones. J Urol. 2004;172(5 Pt 1):1899-902.

13. Lee YH, Tsai JY, Jiaan BP, Wu T, Yu CC. Prospective randomized trial comparing shock wave lithotripsy and ureteroscopic lithotripsy for management of large upper third ureteral stones. Urology. 2006;67(3):480-4; discussion 484.

14. Lopes Neto AC, Korkes F, Silva JL, 2nd, Amarante RD, Mattos $\mathrm{MH}$, Tobias-Machado $\mathrm{M}$, et al. Prospective randomized study of treatment of large proximal ureteral stones: extracorporeal shock wave lithotripsy versus ureterolithotripsy versus laparoscopy. J Urol. 2012;187(1):164-8.

15. Huang CY, Chen SS, Chen LK. Cost-effectiveness of treating ureteral stones in a Taipei City Hospital: shock wave lithotripsy versus ureteroscopy plus lithoclast. Urol Int. 2009;83(4):410-5.

16. Kumar A, Nanda B, Kumar N, Kumar R, Vasudeva P, Mohanty NK. A prospective randomized comparison between shockwave lithotripsy and semirigid ureteroscopy for upper ureteral stones <2 cm: a single center experience. J Endourol. 2015;29(1):47-51.

17. Lam JS, Greene TD, Gupta M. Treatment of proximal ureteral calculi: holmium:YAG laser ureterolithotripsy versus extracorporeal shock wave lithotripsy. J Urol. 2002;167(5):1972-6.

18. Volkin $D$, Shah $O$. Complications of ureteroscopy for stone disease. Minerva Urol Nefrol. 2016;68(6):570-85.

19. Turk C, Petrik A, Sarica K, Seitz C, Skolarikos A, Straub M, et al. EAU Guidelines on Interventional Treatment for Urolithiasis. Eur Urol. 2016;69(3):475-82.

20. Liu DY, He HC, Wang J, Tang Q, Zhou YF, Wang MW, et al.
Ureteroscopic lithotripsy using holmium laser for 187 patients with proximal ureteral stones. Chin Med J (Engl). 2012;125(9):1542-6.

21. Berardinelli F, De Francesco P, Marchioni M, Cera N, Proietti S, Hennessey D, et al. RIRS in the elderly: Is it feasible and safe? Int J Surg. 2017;42:147-51.

22. K. Shigemura TY, M. Yamashita, S. Arakawa, and M., Fujisawa. Efficacy of combining flexible and rigid ureteroscopy for transurethral lithotripsy. Kobe Journal of Medical Sciences. 2010;56(1):E24-E8. 